\title{
Barriers and Facilitators of Community-Based Health Insurance Membership in Rural Amhara Region, Northwest Ethiopia: A Qualitative Study
}

\author{
Getu Debalkie Demissie (iD) \\ Asmamaw Atnafu (iD ${ }^{2}$ \\ 'Department of Health Education and \\ Behavioral Sciences, Institute of Public \\ Health, College of Medicine and Health \\ Sciences, University of Gondar, Gondar, \\ Ethiopia; ${ }^{2}$ Department of Health Systems \\ and Policy, Institute of Public Health, \\ College of Medicine and Health Sciences, \\ University of Gondar, Gondar, Ethiopia
}

Correspondence: Getu Debalkie Demissie Email getud2006@gmail.com
Background: More than 150 million people encounter huge cost of health expenses every year, and most of these treatment seekers face poverty owing to out-of-pocket payments. Community-based health insurance (CBHI) won popularity as a makeshift health financing mechanism for out-of-pocket payments in poor communities. The aim of this study was therefore to explore the facilitators and impediments of enrollment to community-based health insurance in rural parts of the Amhara region, Ethiopia.

Methods: Focus Group Discussion (FGD) was the main data collection instrument supplemented by key informant interview (KII). The FGD participants were selected using a purposive sampling technique. The participants were therefore selected based on their membership status of CBHI (members or non-members). Six FGDs and four KIIs were conducted in November 2019 in three districts. Before analyzing the data, all FGDs and KIIs were transcribed and transferred into ATLAS.ti version 7.1 software. An inductive thematic analysis approach was done, that is, on the basis of major themes emerged from the data.

Results: Low level of awareness, perception of high amount of premium, poor perception of quality of services and lack of trust are the barriers to join community-based health insurance.

Conclusion: There has been low level of awareness and misconception about communitybased health insurance. The major reason to decline to join CBHI was low capacity to pay the premium.

Keywords: community-based health insurance, enrolment, Ethiopia

\section{Introduction}

Globally, more than 150 million people encounter huge cost of health expenses every year, and most of these treatment seekers face poverty owing to out-of-pocket payments (OOP) for health care. Community-based health insurance (CBHI) won popularity as a makeshift health financing mechanism for out-of-pocket payments in poor communities. ${ }^{1,2} \mathrm{CBHI}$ runs by combining resources and risks at the individual and community levels. In similar projects, individuals/families willingly cover set amounts for the benefit of packages involving medical services. ${ }^{3}$

Studies showed that $\mathrm{CBHI}$ schemes can reduce catastrophic health expenditure (CHE) by reducing OOP payments and increasing resource mobilization., ${ }^{4,5}$ Although it has been proved that $\mathrm{CBHI}$ schemes can bring financial protection, its effect and coverage are different in certain contexts and conditions. ${ }^{6,7}$ This shows that conducting similar interventions in different settings cannot be effective unless a variety of factors are taken into consideration for its sustainability. ${ }^{8}$ 
In sub-Saharan Africa, CBHI success is seldom over $10 \%$ of the goal $^{9}$ excluding nations like Rwanda and Ghana. ${ }^{10,11}$ Researchers investigated and identified barriers that diminished enrolment. Unaffordability of payment, poor and limited referral services and weak management which resulted in lack of client trust have been the major identified constraints to enrolment. ${ }^{5,9,12,13}$

A scientific investigation in Burkina Faso pointed out that the cost of premium, inaccessibility of health facilities, poor quality services, absence of health seeking behavior and local notions were the major constraints that held down enrolment initiatives. ${ }^{14} \mathrm{~A}$ research in Tanzania also reported family size, economic status, family members' health condition and awareness of CBHI were the major factors connected with membership. ${ }^{15}$

Despite increases in the supply of health care and increases in the utilization of some specific services in Ethiopia, overall utilization rates remain low. For instance, based on the findings of Ethiopian Demographic and Health Surveys (EDHS), outpatient health care utilization per capita per year has increased only marginally from 0.27 visits in 2000 to 0.3 visits in 2011. The low utilization rates are convoyed by a high dependence on OOP spending to finance health care. The FMoH (2010) estimated that the three main sources of health-care financing in Ethiopia are local and international donors (40\%), OOP spending by health-care users (37\%), and central and local governments $(21 \%)$. The remainder (about $2 \%$ ) is covered by employers and other private insurance schemes. ${ }^{16}$

In 2011, the Ethiopian government introduced CBHI as a pilot project in 13 districts of the four major regional states of the country (Tigray, Oromia, Amhara and SNNP) which was then expanded to additional 161 districts in 2013. This project scored substantial success in the initial stage but dropped in the following years, that is, the enrolment decreased by $18 \% .{ }^{17}$ While the scheme has been introduced by the government, the community determines whether or not to join the scheme since it is "community-based". Enrollment was done in a household, not on an individual basis, to reduce the possibility of adverse selection. The CBHI benefit package covers all outpatient and inpatient services at the health center and nearby hospital levels except false teeth, eye glasses, and cosmetic procedures. $^{18}$

In Ethiopia, some studies tried to assess the determinants of CBHI but none of them examined the barriers of CBHI enrolment adequately specifically in Amhara region. ${ }^{19}$ Therefore, the aim of this qualitative study was to explore barriers and facilitators of $\mathrm{CBHI}$ enrolment thereby to provide information for policy makers to improve the implementation of CBHI.

\section{Methods}

\section{Study Setting}

The study was conducted in the Amhara regional state. Out of 167 rural districts, three of them were chosen purposively (Libo Kemekem, Fogera, and Farta) due to poor implementation of CBHI and accessibility of transport. The data were collected in November, 2019.

\section{Data Collection and Sampling}

FGD was the main research method supplemented by key informant interview. FGD was preferred to in-depth interview to involve group interactions and gain rich information about perceptions and experiences relating to community-based health insurance. ${ }^{20}$ Six FGDs (3 from CBHI members and 3 others from CBHI non-members) and 4 key informants were conducted. The FGD participants were farmers, while the key informants were community health extension workers and CBHI focal persons. There were about 10-12 members in each FGD. Both FGDs and KIIs were audio-recorded in Amharic and lasted 1-1.5 hours and 40-45 minutes, respectively.

A pretested interview guide was used both FGDs and KIIs in Lay Armachiho district which has similar features with the study areas. All FGDs and KIIs were led by a moderator and notes were written by an independent note-taker. Purposive sampling, specifically a mix of criteria-based and maximum variation sampling technique, was used based on CBHI membership status for sampling technique. ${ }^{21}$ Exploratory research design was used in this study. Data were gathered through a semi-structured interview which touched the following themes: sociodemographic characteristics, CBHI awareness, perception of affordability of the payment, renewalship for CBHI and trust in CBHI, and quality of service.

\section{Data Analysis}

Before analyzing the data, all FGDs and KIIs were transcribed to Amharic, and translated to English. ATLAS.ti version 7.1 software package was used to aid the analysis of the data. The transcribed FGDs and KIIs texts were read several times to clearly understand the transcribed and translated data. We read the transcripts line by line; 
codes were developed by considering the objective of the study and the possible meanings and then codes were clustered into categories and subcategories. The categories and subcategories were modified according to the major themes emerged from the data. An inductive thematic analysis approach was used. ${ }^{22}$ Initial coding was done by the lead author and commented on by the co-author.

\section{Trustworthiness of the Study}

The participants shared their opinions as to whether the findings were in line with their experiences. The researchers also had prolonged and deep engagement with the qualitative data. A peer checking was done on the second review of the transcripts, codes and concepts on which several colleagues took part. Documentation was done throughout the study to ensure the conformability of the findings. Purposive sampling (maximal variation in participant's selection) and the guidance of experts experienced in qualitative inquiry to ensure dependability and transferability of the finding.

\section{Ethics Approval and Consent to Participate}

Ethical clearance was obtained from the University of Gondar, Institutional Review Board (IRB) with IRB number of 1610/003-007. As the study was conducted in rural areas, most of the participants were not able to read and write. Therefore, verbal consent was obtained from each respondent before data collection by explaining the purpose of the study and this procedure was approved by the review committee. Finally, strict confidentiality was also maintained through anonymous recording of responses and the study was conducted in accordance with the declaration of Helsinki.

\section{Results}

A total of six FGDs (3 CBHI members and 3 nonmembers) and 4 key informant interviews were conducted. All the FGD participants were farmers, and almost $50 \%$ of them were female participants (Table 1).

In this qualitative study 6 themes were identified: (I) awareness of households about the benefits and principles of CBHI, (II) reasons for declining to join CBHI, (III) readiness for CBHI membership renewal, (IV) perception of premium amount of CBHI, (V) trust in CBHI, and (VI) qualities of services provided by the schemes. Various opinions were often expressed in the key informant interviews and focus group discussions by both members and non-members of the community-based health insurance.
Table I Socio-Demographic Characteristics of FGDs Participants

\begin{tabular}{|c|c|c|}
\hline $\begin{array}{l}\text { Socio-Demographic } \\
\text { Variables }\end{array}$ & $\begin{array}{l}\text { CBHI } \\
\text { Members }\end{array}$ & $\begin{array}{l}\text { Non-CBHI } \\
\text { Members }\end{array}$ \\
\hline $\begin{array}{l}\text { Gender } \\
\text { Male } \\
\text { Female }\end{array}$ & $\begin{array}{l}\mid 8(51.0 \%) \\
\mid 7(49.0 \%)\end{array}$ & $\begin{array}{l}17(48.5 \%) \\
18(51.5 \%)\end{array}$ \\
\hline $\begin{array}{l}\text { Age } \\
20-35 \\
36-50 \\
51-65 \\
>65\end{array}$ & $\begin{array}{l}5(45.0 \%) \\
27(77.0 \%) \\
2(5.6 \%) \\
I(2.7 \%)\end{array}$ & $\begin{array}{l}9(25.7 \%) \\
17(49.0 \%) \\
4(11.5 \%) \\
5(15.0 \%)\end{array}$ \\
\hline $\begin{array}{l}\text { Educational status } \\
\text { Illiterate } \\
\text { Able to read and write } \\
\text { Primary school }\end{array}$ & $\begin{array}{l}24(68.6 \%) \\
3(8.5 \%) \\
8(22.0 \%)\end{array}$ & $\begin{array}{l}29(82.5 \%) \\
3(8.5 \%) \\
3(8.5 \%)\end{array}$ \\
\hline $\begin{array}{l}\text { Occupation } \\
\text { Farmer }\end{array}$ & $35(100 \%)$ & $35(100 \%)$ \\
\hline
\end{tabular}

\section{Awareness on $\mathrm{CBHI}$}

Although the majority of the members and non-members of CBHI were aware of the scheme, a good number of community members were still not very clear as can be understood below.

"CBHI focal persons simply informed us to be members, but they did not tell us about the benefits and the principles of governing its implementation in detail." (P2, FGD1, CBHI non-member)

This idea was confirmed by one of the community health extension workers who explained that there were no sufficient awareness creation sessions.

No specific meetings were conducted for CBHI, so we tried to use other meetings which were prepared for other purposes to create awareness about the scheme. We believe that if some information is given to the community, we could develop their awareness about CBHI through discussion. However, awareness sessions on the issue were not given. (KII1, Farta District)

\section{Reasons for Declining to Join $\mathrm{CBHI}$ Membership}

The major reasons for the majority of non-members of FGD participants for declining to join CBHI membership were financial constraints, 
"Currently we have different payment responsibilities, like taxes, student educational fees which makes difficult for insurance payment.” (P3, FGD3, CBHI non-member)

\section{Readiness for Renewalship}

A large number of CBHI members were not ready to renew their membership. One of the FGD participants explained that:

We have been discussing the issue during our coffee and local beer ceremonies. May be, persons with chronic sicknesses are ready to renew their membership, but members who have not been sick for more than a year are not ready because they did not use their previous payments. They said we will be treated by selling our goats when we do not have money. (P10, FGD5, CBHI member)

A key informant who is the CBHI focal person of the district confirmed,

At the beginning $33 \%$ of our target population joined CBHI. But these days, we have faced challenges to get new members and membership renewals. At present membership renewal rate is less than $10 \%$. (KII4, Addiszemen District)

\section{Perception About CBHI Premium}

The majority of both members and non-members of CBHI complained that the annual increase in premium of $\mathrm{CBHI}$ is not fair, but there were also some participants who thought that the payment was fair.

The premium for a family member of five was around ETB 202( $\$ 1$ is equivalent to 35 ETB based on the current exchange rate), which was affordable to the community. However, this premium increased by ETB 38 in this year. So, the community is worried about the increment which is beyond their capacity to pay. (P4, FGD1, CBHI member)

On the other hand, both some members and non-members of CBHI explained that the premium was fair.

I have known a non-member lady whose child got sick, and she went to Bahir Dar and spent not more than ETB 300. Another CBHI member paid only transport costs for a similar case. So, the premium is much lower than the health care expenses. (P4, FGD6, CBHI member)

\section{Trust on $\mathrm{CBHI}$}

The majority of FGD participants have trust in CBHI.
I and other persons believe that this health insurance payment is only for our health, and I know a woman who was seriously sick and got treatment at Bahir Dar hospital. The treatment cost more than ETB 9000, but she paid only five hundred for the card. The insurance covered the cost. She asked what would happen if she was not a member? When we look at this, it has high benefits. So, we all believe the payment is used for our health, not for other purposes. (P8, FGD2, CBHI non-member)

On the other hand, some of FGD participants have not trust,

I joined the scheme when the payment was ETB 85, but next year the payment rose to ETB 144, without any services due to delays in the issuance of identification cards. In the meantime, I and my child got sick and went to the health center, but they told us we needed to renew our membership which disappointed us very much. Then, we started to think about the importance of insurance. Therefore, we decided to leave the scheme. (P10, FGD4, CBHI member)

\section{Perception on Quality of Care}

The majority of both members and non-members criticized the quality of services from different perspectives. Criticisms focused on three aspects: long waiting times, excessive prescription (non-CBHI members), and differential treatment depending on patient membership status.

The government has provided this great opportunity, but the health professionals serving at health centers are disappointing. There are no enough drugs, no good services; they have only empty offices. We get better services when we are referred to higher health service institutions, like hospitals. For example, I had a neighbor who had breast cancer; she went to Bahir Dar hospital and got very good service without payment. So, I can say the insurance is a very good mechanism for good health services; the problem is with the health providers. (P8, FGD3, CBHI member)

A key informant from community health extension workers confirmed that,

The majority of CBHI members are not satisfied with the services provided by health facilities. People are complaining about service providers. They are considering CBHI member patients healthy and thinks that they come to health facilities because they have free cards. (KII3, Farta District)

\section{Discussion}

The aim of this study was to explore the barriers and facilitators of CBHI membership schemes. Low level of 
awareness, perception of the amount of premium and quality of services, and trust in CBHI were identified as the main barriers to membership in CBHI.

The study revealed that although the majority of members and non-members have awareness, there are groups who were not aware enough about CBHI benefits and principles. This result is similar to other findings which showed that inadequate knowledge and understanding of insurance and CBHI principles are one of the obstacles to enrolment. ${ }^{23,24}$ Poor knowledge of insurance is likely due to poor communication and sensitization campaigns that do not manage CBHI to convey information in an effective manner.

In this study, the main reasons to be membership among the current CBHI members were preventing out-of-pocket payment for emergency. On the other hand, a significant number of non-members of $\mathrm{CBHI}$ raised that a high amount of premium was a barrier to be membership. A study conducted in Tanzania reported a similar finding. ${ }^{15}$ This study also revealed that the majority of both members and non-members of CBHI complained that the premium of $\mathrm{CBHI}$ was increasing yearly which pushed them to decline from CBHI membership. This is supported by other qualitative studies. ${ }^{14,15}$

Different studies also showed that premium is one of the main factors associated with CBHI enrolment. ${ }^{25}$ Rural poor people complained that the flat rate nature of premium prevents them from enrolment. Therefore, strategies which enhance the flexibility of the payment by considering the poorest should be planned. ${ }^{26}$

This study showed that providers do not give similar or equal services to patients who are CBHI members and nonmembers. Members perceived that CBHI non-members are more respected and treated. This is supported by other studies. $^{23,24}$ The respect of care providers is one of the main factors for enrolment in $\mathrm{CBHI}{ }^{27}$

According to this study, lack of transparency has been one of the constraints for enrolment of CBHI. A similar finding was reported in Uganda. ${ }^{23}$ The lack of transparency in CBHI administration resulted in client distrust and decreased enrolment in the scheme. ${ }^{14,23,27-29}$ Premium rates and management of funds set without community participation also affect the sustainability of CBHI. ${ }^{30,31}$

\section{Conclusion}

There is a low level of awareness about the benefits and principles of CBHI. The major reason for declining CBHI membership is due to a lack of capacity to pay the premium. Therefore, awareness creation programs in the scheme, avoiding flat rate payments (stratified premium based on the economic status of households), ensuring transparency, and monitoring the quality of services are essential empowering tools for increasing enrolment.

\section{Abbreviations}

CBHI, community-based health insurance; OOP, out-ofpocket payment; FGD, focused group discussion; KII, key informant interview; LMICs, low- and middle-income countries.

\section{Data Sharing Statement}

The data could be obtained upon reasonable request from the corresponding author.

\section{Acknowledgment}

We would like to express our thanks and appreciation to the study participants for their willingness to provide the required information. We also want to thank reviewers for devoting their time to improve this manuscript.

\section{Author Contributions}

All authors made a substantial contribution to the conception and design, acquisition of data or analysis and interpretation of the data, took part in drafting, revising it critically for important intellectual content; gave final approval for the version to be published; have agreed on the journal to which the article has been submitted; and agree to be accountable for all aspects of the work.

\section{Funding}

There is no funding to report.

\section{Disclosure}

The authors declare that they have no conflicts of interest for this work.

\section{References}

1. Dror DM, Preker AS. Social Reinsurance: A New Approach to Sustainable Community Health Financing. Washington DC: The World Bank; 2002.

2. Preker AS, Carrin G. Health Financing for Poor People: Resource Mobilization and Risk Sharing. World Bank; 2004.

3. Parmar D, Souares A, De Allegri M, Savadogo G, Sauerborn R. Adverse selection in a community-based health insurance scheme in rural Africa: implications for introducing targeted subsidies. $B M C$ Health Serv Res. 2012;12(1):1-8. doi:10.1186/1472-6963-12-181

4. Ranson MK. Reduction of catastrophic health care expenditures by a community-based health insurance scheme in Gujarat, India: current experiences and challenges. Bull World Health Organ. 2002;80 (8):613-621. 
5. Ekman B. Community-based health insurance in low-income countries: a systematic review of the evidence. Health Policy Plan. 2004;19(5):249-270. doi:10.1093/heapol/czh031

6. Soors W, Devadasan N, Durairaj V, Criel B. Community Health Insurance and Universal Coverage: Multiple Paths, Many Rivers to Cross. Geneva: World health report; 2010.

7. Spaan E, Mathijssen J, Tromp N, McBain F, Ten Have A, Baltussen R. The impact of health insurance in Africa and Asia: a systematic review. Bull World Health Organ. 2012;90(9):685-692. doi:10.2471/BLT.12.102301

8. Edwards N, Barker PM. The importance of context in implementation research. J Acquir Immune Defic Syndr. 2014;67(2):S157-62. doi:10.1097/QAI.0000000000000322

9. De Allegri M, Kouyaté B, Becher H, et al. Understanding enrolment in community health insurance in Sub-Saharan Africa: a populationbased case-control study in rural Burkina Faso. Bull World Health Organ. 2006;84(11):852-858. doi:10.2471/BLT.06.031336

10. Lu C, Chin B, Lewandowski JL, et al. Towards universal health coverage: an evaluation of Rwanda Mutuelles in its first eight years. PLoS One. 2012;7(6).

11. Mills A, Ataguba JE, Akazili J, et al. Equity in financing and use of health care in Ghana, South Africa, and Tanzania: implications for paths to universal coverage. Lancet. 2012;380(9837):126-133. doi:10.1016/S0140-6736(12)60357-2

12. Kamuzora P, Gilson L. Factors influencing implementation of the community health fund in Tanzania. Health Policy Plan. 2007;22 (2):95-102. doi:10.1093/heapol/czm001

13. Ozawa S, Walker DG. Trust in the context of community-based health insurance schemes in Cambodia: villagers' trust in health insurers. Adv Health Econ Health Serv Res. 2009:107-132.

14. De Allegri M, Sanon M, Sauerborn R. To enroll or not to enroll? A qualitative investigation of demand for health insurance in rural West Africa. Soc Sci Med. 2006;62(6):1520-1527. doi:10.1016/j. socscimed.2005.07.036

15. Macha J, Kuwawenaruwa A, Makawia S, Mtei G, Borghi J. Determinants of community health fund membership in Tanzania: a mixed methods analysis. BMC Health Serv Res. 2014;14(1). doi:10.1186/s12913-014-0538-9

16. FMOH of Ethiopia. Health sector development programme IV: 2010/11-2014/15; 2010.

17. Abt, Inc. A Health Financing Reform in Ethiopia: Results and Progress to Date. Addis Ababa; 2013.

18. Mebratie A, Sparrow R, Alemu G, Bedi AS. Community-based health insurance schemes: a systematic review (ISS Working Paper No 568). World Development. 2013:568.
19. Atafu A, Kwon S. Adverse selection and supply-side factors in the enrollment in community-based health insurance in Northwest Ethiopia: a mixed methodology. Int J Health Plan Manag. 2018;33 (4):902-914. doi:10.1002/hpm.2546

20. van E, Angehrn Z. How to ... conduct a Focus Group Discussion (FGD). Methodological manual. 2017.

21. Patton M. Qualitative Evaluation and Research Methods. Beverly Hills; 1990:169-186.

22. Thomas D. A general inductive approach for analyzing qualitative evaluation data. Am J Eval. 2006;27(2):237-246. doi:10.1177/ 1098214005283748

23. Basaza R, Criel B, Van der Stuyft P. Community health insurance in Uganda: why does enrolment remain low? A view from beneath. Health Policy (New York). 2008;87(2):172-184. doi:10.1016/j. healthpol.2007.12.008

24. Criel B, Waelkens M. Declining subscriptions to the Maliando mutual health organization in Guinea Conakry (West Africa): what is going wrong? Soc Sci Med. 2003;57(7):1205-1219. doi:10.1016/S02779536(02)00495-1

25. Jehu-Appiah C, Aryeetey G, Agyepong I, Spaan E, Baltussen R. Insurance scheme in Ghana household perceptions and their implications for enrolment in the national health insurance scheme in Ghana. Health Policy Plan. 2012;27(3):222-233. doi:10.1093/heapol/czr032

26. Onwujekwe O, Onoka C, Uzochukwu B, Okoli C, Obikeze E, Eze S. Is community-based health insurance an equitable strategy for paying for healthcare? Experiences from southeast Nigeria. Health Policy (New York). 2009;92(1):96-102. doi:10.1016/j.healthpol.2009.02.007

27. Schneider P. Trust in micro-health insurance: an exploratory study in Rwanda. Soc Sci Med. 2005;61(7):1430-1438. doi:10.1016/j. socscimed.2004.11.074

28. Turcotte-Tremblay A, Haddad S, Yacoubou I, Fournier P. Mapping of initiatives to increase membership in mutual health organizations in Benin. Int J Equity Health. 2012;11(1):1-5. doi:10.1186/1475-927611-74

29. Dienye PO, Brisibe SF, Eke R. Sources of healthcare financing among surgical patients in a rural Niger Delta practice in Nigeria. Rural Remote Health. 2011;11(1):107.

30. Kyomugisha E, Buregyeya E, Ekirapa E, Mugisha J, Bazeyo W. strategies for sustainability and equity of prepayment health schemes in Uganda. Afr Health Sci. 2009;9(2):S59-65.

31. Van-dormael BC, Lefevre P, Menase U, Van-lerberghe W, Van Lerberghe W. Voluntary health insurance in Bwamanda, democratic republic of Congo: an exploration of its meanings to the community. Trop Med Int Health. 1998;3(8):640-653. doi:10.1046/j.13653156.1998.00286.x
ClinicoEconomics and Outcomes Research

\section{Publish your work in this journal}

ClinicoEconomics and Outcomes Research is an international, peerreviewed open-access journal focusing on Health Technology Assessment, Pharmacoeconomics and Outcomes Research in the areas of diagnosis, medical devices, and clinical, surgical and pharmacological intervention. The economic impact of health policy and health systems organization also constitute important areas of coverage. The manuscript management system is completely online and includes a very quick and fair peer-review system, which is all easy to use. Visit http://www.dovepress.com/testimonials.php to read real quotes from published authors. 